\title{
Dysregulated neutrophil function in individuals with alpha-1 antitrypsin deficiency caused by modified membrane cholesterol content.
}

\author{
Bakr Jundi", Michelle White, Noreen Lacey, Noel G McElvaney, Emer Reeves \\ From 4th International Conference for Healthcare and Medical Students (ICHAMS) 2014 \\ Dublin, Ireland. 24-25 October 2014
}

\section{Background}

Individuals with alpha-1 antitrypsin (AAT) deficiency (AATD) are predisposed to early-onset emphysema and neutrophils are the primary effector cells responsible for the pathological manifestations of AATD lung disease. As AAT interacts directly with the circulating neutrophil membrane [1], the question that this project addressed was: are AATD neutrophils structurally and functionally altered? The aim of this study was to explore a link between disrupted membrane structure and impaired trafficking of cholesterol in AATD neutrophils.

\section{Methods}

Circulating neutrophils were purified from blood of patients with AATD and from healthy control individuals $(n=7)$. Membranes and cytosols were isolated from neutrophils by sucrose-gradient ultracentrifugation. Cholesterol and calcium levels were fluorometric quantified and calpain levels measured using a calpain activity assay. Caveolin-1 expression was examined by Western blot analysis. Statistical comparisons were performed by Student's t-test.

\section{Results}

Neutrophil cytosols of AATD individuals had increased calcium concentrations $(n=7, p=0.04)$ and activation of the calcium dependent protease calpain $(\mathrm{n}=7, \mathrm{p}=0.01)$. Furthermore, levels of the cholesterol trafficking protein caveolin-1 were significantly lower in AATD neutrophil cytosols $(n=6, p=0.01)$ leading to significantly decreased membrane cholesterol content when compared to healthy control cells $(n=5, P=0.045)$.

\section{Dept. of Medicine, Respiratory Research, Beaumount Hospital, Dublin 9,} Ireland 